\section{Laparoscopic percutaneous endoclose closure of a paraumbilical hernia defect}

\author{
Amir Sadri, ${ }^{1}$ Eyston Vaughan-Huxley, ${ }^{1}$ \\ David Nott ${ }^{2}$
}

${ }^{1}$ Royal London Hospital; ${ }^{2}$ Chelsea \& Westminster Hospital, London, UK

\section{Abstract}

We describe a technique of endoloop closure of a paraumbilical abdominal wall hernia defect when using $5 \mathrm{~mm}$ laparoscopic ports.

\section{Introduction}

Laparoscopic repair of a paraumbilical hernia is a well recognised technique. There are several methods for tackling the defect left in

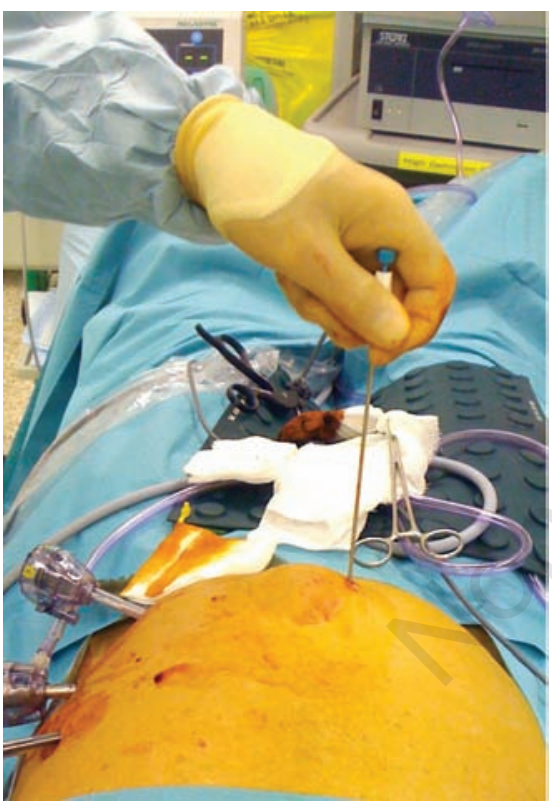

A

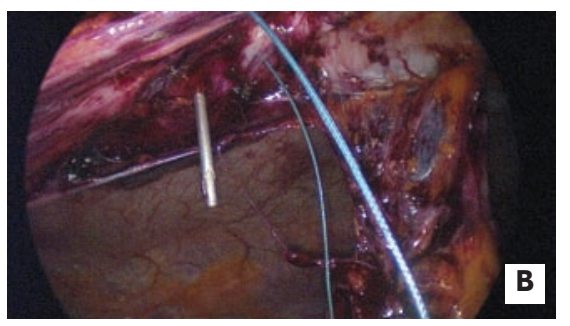

Figure 1. A) Insertion point of endoclose. B) Laparoscopic view of endoclose bite of hernial defect edge. the anterior abdominal wall before placement of a mesh. However, the conventional laparoscopic suture technique is not possible if $5 \mathrm{~mm}$ ports are used as the needle cannot pass through. We describe a technique of endoclose closure of the abdominal wall defect without resorting to larger ports or needle closure.

\section{Technical note}

The borders of the defect are delineated by dissection. An endoclose is passed through one side of the defect, a suture thread anchored in position in the standard fashion (Figures 1A and B).

The next bite is then performed thus. Without making another stab incision, the endoclose is tunneled subcutaneously and a second bite is taken on the other side of the defect (Figures 2A and 2B).

The suture from the first bite is pulled through the endoclose again. This will create
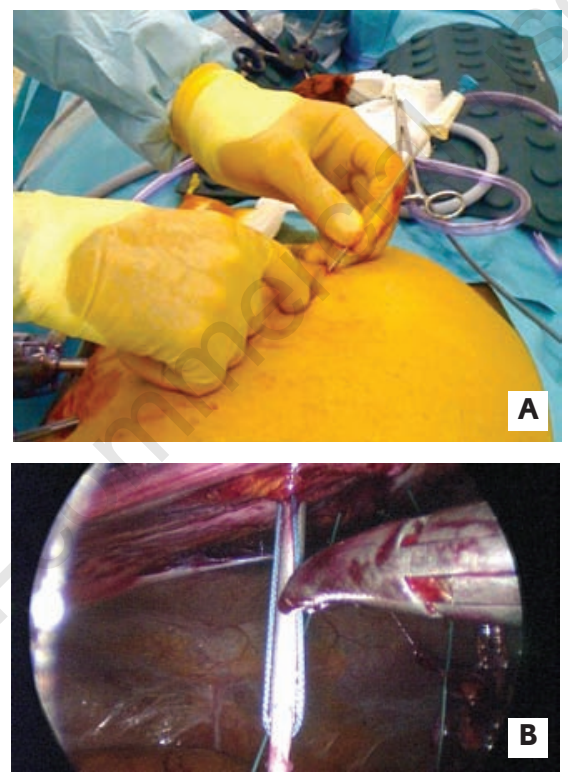

Figure 2. A) Subcutaneous tunneling of endoclose to bite the opposite side of the defect. B) Laparoscopic view of figure 2A with the suture fed into the endoclose.

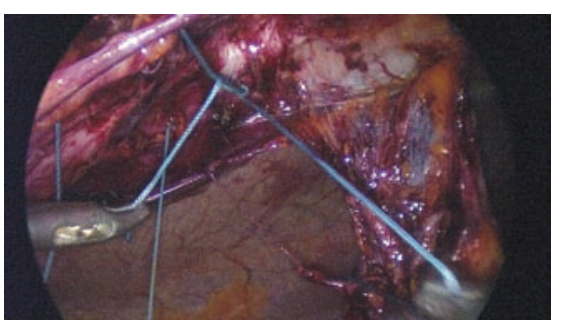

Figure 3. Final position of sutures ends using the endoclose. A knot is being tied to close the defect.
Correspondence: Eyston Vaughan-Huxley, Royal London Hospital, Whitechapel Road, Whitechapel, London E1 1BB, UK.

E-mail: e.vaughan-huxley@doctors.org.uk

Key words: endo-close, percutaneous, laparoscopic, hernia repair.

Received for publication: 22 June 2011. Accepted for publication: 21 October 2011.

This work is licensed under a Creative Commons Attribution NonCommercial 3.0 License (CC BYNC 3.0).

(C) Copyright A. Sadri et al., 2011

Licensee PAGEPress, Italy

Surgical Techniques Development 2011; 1:e29

doi:10.4081/std.2011.e29

the two bites on the either side of the defect (Figure 3).

The defect is then closed by tying a knot. This procedure can be performed as many times as required to close the defect.

\section{Discussion}

The endoclose tunneling technique allows closure of the defect in the abdominal wall before the application of a mesh. The above technique is useful if the surgeon prefers not to resort to larger ports to allow needles to enter the abdomen. Smaller ports also have the advantage of a smaller scar and a reduced risk of port-site incisional hernia. 